Revista Iberoamericana, Vol. LXIX, Núm. 202, Enero-Marzo 2003, 15-29

\title{
SIN NOVIO NI ÉPICA: BREVE ARQUEOLOGÍA DEL AGUANTE (MADRE DE TODAS LAS COSAS)
}

\author{
POR \\ AMIR HAMED \\ escritor, periodista, redactor responsable de la revista CRAC, \\ webmaster de $\mathrm{H}$ enciclopedia \\ Este es el aguante \\ Hasta yo lo vi \\ Este es el aguante \\ Decímelo a mí \\ Y si no te gusta \\ Te podés matar \\ Este es el aguante \\ Este es mi lugar \\ Este es el aguante \\ Esto es Rock \& Roll \\ Charly García, El Aguante (1998)
}

Tras que Edipo, a las puertas de Tebas, resuelve el enigma del cuadrúpedo que es bípedo y luego trípode al que lo somete la Esfinge, ésta se autoaniquila; la respuesta, antes del héroe de los pies hinchados, era impronunciable por banal: bastaba con decir "el hombre”. Edipo, que fue hermano de sus hijos y nieto de su suegra, fue parejamente banal y atrevido. Otro al que lo baladí no ha acobardado es Charly García, quien presumiblemente fue sometido a un programa de preguntas y respuestas cuyo botín era capturado tras resolver el acertijo de "qué es eso que modificó la etiqueta de las gallinas, la modulación de los cantantes de rock platenses, que lleva a los niños que están lejos de la pobreza a pedir monedas por las calles de Montevideo y habrá de rebautizar la Plaza de Mayo, en Buenos Aires”. Es de barajar que los productores del programa hayan descansado en la nula mención que, históricamente, en letras o entrevistas había hecho García de los lugares comunes de los pelotaris (es uno de los pocos de la farándula argentina a los que se le desconoce partidismo deportivo), pero lo cierto es que, luego de la respuesta, quedaron a expensas de una invitación al suicidio.

NAda del aguante me es AJeno

El ganador, García, siempre a la vanguardia, con sonoro palmetazo en la frente, reconoce que llegó tarde pero que, a la vez, siempre estuvo ahí: "hasta yo lo vi/decímelo 
a mí”. Error del inquisidor considerar al aguante un evento deportivo. Error (asumido) por García, la anagnórisis lerda. Si él mismo, en “Chipi Chipi”, definió su poética como "detectora” (“yo sólo tengo esta pobre antena/que me transmite lo que decir”) y se ha convertido en gurú por dar la alarma en el momento justo, aquí fue como recibir un pelotazo que descalabra el entrecejo y despertar a la revelación anacrónica de que él, una vida a la vanguardia, había nacido para la pasión añeja de eso mismo que estraga gargantas entre los hinchas; una herida abrasiva, envolvente, que con todo barre. Hoy, 2002, en el Río de la Plata, todo es aguante, esfinge de mil caras que, entre otras cosas, tiene su propia Plaza, la misma que fuera de los padres y madres de Mayo, frente a la Casa Rosada. Aquellos más lentos que García no dejarán de percibir (y en muchos casos, de temer) que se trata de un cambio ideológico e institucional que, entre otras cosas, marca la clausura de los próceres de Mayo y los colores nacionales diseñados por Belgrano en favor de la heráldica de los barra brava, incorporada a los movimientos de resistencia de eso que algunos han dado en llamar sociedad civil. Pero como todo aquello ubicuo, y como en la neurótica letra de García, que escamotea definiciones, el aguante es inasible como la brisa; está en todas partes pero nadie termina de saber qué es. Está en las camisetas que son atavío casi obligado de chicas o chabones en los pubs del Tigre o Barrio Norte, en Buenos Aires, o de Punta Carretas o Carrasco, en Montevideo, y también en las bailantas; está en miles de páginas de la Internet, en la dicción rejuvenecida de las tribus urbanas, en los pesos y patacones que se limosnean para el vino o la cerveza o por el mero imperativo de la limosna; en la resistencia casi sorda al pacto cívico, al intercambio laboral, a la geopolítica de los ganadores; está en un programa televisivo de Torneos y Competencias, llamado "El aguante”, en la atmósfera cada vez más gesticulante de las calles, en la caja de vino que va tomando una muchacha, a las siete de la tarde, rumbo a la rambla de Palermo, en Montevideo, pasando junto a la embajada de Estados Unidos, custodiada por patrulleros; está lejos de Dios, es de presumir, pero igual que con el trino y uno, y con el rock and roll, todo comenzó casi en sigilo, en un par de iglesias (llegó para quedarse); pero a diferencia del Dios atronador que impuso sus tablas en el Sinaí, el aguante necesita ser sometido a predicados.

EN EL PRINCIPIO FUE LA GALLINA

Tras cierta sonora derrota deportiva, la de un equipo argentino contra uno uruguayo, en 1966, las gallinas comenzaron a asistir a la tribuna de Boca Juniors ataviadas con una camiseta de River Plate. Nadie sabía si se trataba de ponedoras o cluecas y se conjeturaba que no habían pagado entrada. Nadie, siquiera, podía escuchar su cococó, pero a ninguno pasó por alto que, a través de las gallinas, los hinchas de Boca ratificaban que su rivalidad con River Plate trascendía cualquier nacionalismo: más aún, explicaban, por medio de esa ave incapaz del vuelo, por qué ellos no eran de River, es decir, por qué adherían al campo azul, franjeado de oro. ${ }^{1}$ En ocasiones, las ovíparas, con revoloteo de plumas y sus tradicionales y escasamente atléticos saltitos, eran arrojadas al verde césped. En la década

\footnotetext{
${ }^{1}$ Es decir, los colores de Boca Juniors.
} 
siguiente creció la granja cuando, revanchista, la barra de River arrojó, marrón y hocicudo bajo el oroazul de la casaquilla, un cerdo. No engañarse con la progresión edípica: dos patas gallináceas, cierto, cuatro porcinas, pero el aguante es un miriápodo, que todavía era nonato. Lo que sí resultaba de todos modos advertible era que las hinchadas habían abolido la distancia sacra del campo civilizador que era la cancha; sistemáticamente, para deleite de las cámaras, arrojaban rollos de papel (higiénico, de calculadora) que los ilusos tras la pantalla blanco y negro confundían con serpentinas. El rollo que iba cayendo dejaba una estela que, de alguna forma, unía los dos mundos: el tablón populoso y el espacio regimentado que poblaban los héroes.

Esto no dejaba de transgredir el modelo civilizador de la modernidad platense. Baste recordar que, si bien durante las primeras décadas del siglo xx, el fútbol era el jolgorio del campo abierto (la cancha un lamparón de pampa o plenillanura entre las ciudades que crecían y humeaban al influjo de los inmigrantes y, en el cuero de vaca hecho pelota, rodaba de aquí para allá el souvenir de la sociedad pastoril y anárquica que tanto molestara a Sarmiento). ${ }^{2}$ De todas formas comportaba una amable trampa para matreros nostálgicos. Por más que al principio fuera en el Plata un festejo de habilidades e individualismos, el football inoculaba reglas y, más aún, cumplía con el fin disciplinante con el que los ingleses, a partir del siglo xix, impusieron la práctica de deportes colectivos y de competencia. ${ }^{3}$ La rivalidad deportiva (por más que el deporte sea sucedáneo de la guerra) era un aspecto más de la vida en la civitas, por más pasional y omnipresente que ésta fuera en el Plata. Para la sociedad de tabla rasa y pequeña burguesía igualitaria que surgió en el siglo xx en el Uruguay parido por los gobiernos de José Batlle y Ordóñez, los tempranos triunfos deportivos (campeonatos olímpicos de 1924 y 28, mundial del 30), que se estiraron - tras el paréntesis de entreguerras — hasta 1950, hicieron del fútbol y la casaca celeste que adquirió el seleccionado un aparato integrador tras el que se apiñaron criollos e inmigrantes. ${ }^{4}$ Las carreras de los políticos comenzaban en instituciones deportivas,

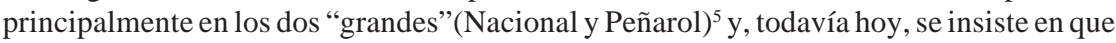

${ }^{2}$ A diferencia del extremadamente disciplinado basketball, deporte estrictamente citadino, cronometrado con infinidad de infracciones, de impulso cenital como los edificios y rascacielos. Al respecto, véase Verdú.

${ }^{3}$ En el siglo xix los alemanes tuvieron una época de apogeo de su modelo, el Turnen (gimnasia), cuyo objeto no era la competencia sino mantener el cuerpo saludable, resaltar las formas corporales y fortalecer el espíritu y el coraje ante el peligro. Los atletas alemanes decimonónicos tenían especial interés en vincular la actividad física con el crecimiento moral e intelectual. Tampoco otra de las variantes que trajo ese siglo, la gimnasia sueca, en la cual los movimientos humanos eran considerados como si formaran parte de una máquina, era competitiva. Pero los ingleses lograron imponer, casi como extensión cultural del imperio, un modelo deportivo asociado, en el que equipos se contraponen a otros equipos en un juego o campeonato. Quienes al comenzar el juego son iguales por definición, son diferentes al final, con un ganador y uno o varios perdedores. Ése es el modelo que luego, a través del olimpismo, se consagraría como "natural".

${ }^{4}$ Si bien habían algunos vascos y gallegos, en las primeras décadas del siglo los jugadores uruguayos eran, en su mayoría, de origen italiano, algo que se mantuvo en Argentina durante toda la centuria. Por otra parte, siempre ha habido algún afrouruguayo inscrito en los grandes triunfos.

${ }^{5}$ Todavía hoy se puede encontrar que el ex dos veces presidente de la República, Julio María Sanguinetti, es presidente honorario de Peñarol y su hijo, diputado, integra la directiva del club que 
el fútbol es el mejor embajador uruguayo, es decir, aquello que hace al país conocido fuera de fronteras. Se ha afirmado que en Argentina, durante el medio siglo, la relación entre balompié y nacionalidad se volvió indisoluble; ${ }^{6}$ lo que aquí cumple recordar, sin embargo, es que en esa edad en la que reinó el bombo populista de Juan Domingo Perón (activo simpatizante de Racing), los footballers jugaban con camisas con cuello y abotonadas: la interpelación a “mis descamisados” que hacía Evita tendía a unificar a las masas más allá de divisas deportivas.

Como hongos, en el Plata, iban creciendo los estadios, diseñados para apacentar público sobre cemento - mientras los atletas se deshidrataban y pateaban-, que venían a cerrar el anillo ciudadano: en un ágora verde, se dirimían diferencias. Amparados en su falta de imaginación y su temor escolar a la reiteración de términos, esos paladines conocidos como cronistas deportivos, empecinados dispositivos de reproducción ideológica del Estado, generaron un lexicón edulcorado que trataba de resolver tensiones de clase y que, todavía hoy, se hace sentir en un complejo sistema de paráfrasis, parónimos y metonimias que progresivamente dejaron de interpelar. Por décadas, a los de River se los llamó "millonarios”, y “xeneixes” a sus archirrivales de Boca (por su cercanía con el estuario). Es en Uruguay donde se verifica que, por más que remitiera a diferencias de clase, este tipo de terminología buscaba lenificar enconos supradeportivos: allí los del Club Nacional de Fútbol, equipo fundado por universitarios, cuya casaca tenía cosido un bolsillo azul, eran llamados "bolsilludos", es decir, acaudalados, por los adherentes a su enconado rival, Peñarol, con origen en las compañías inglesas de ferrocarril. Para ese país batllista el vocablo "bolsilludo" era agresivo, tanto como la palabra "manya”, con la que los de Nacional motejaban a sus adversarios. El relato evemerístico responde a las primeras décadas del siglo, cuando uno de esos próceres “aurinegros” pasó a defender la odiada "tricolor”. Aunque el profesionalismo todavía no se declaraba oficialmente, era practicado entre las instituciones más prósperas, y el “transferido” Carlos Scarone, que de Peñarol había pasado a Boca Juniors, vuelve a Uruguay para ponerse la del bolsillo. Una versión dice que en 1915 jugó su primer clásico siendo reiteradamente agredido por sus ex compañeros, que lo perseguían en una implacable vendetta de noventa minutos. Cansado de revolcones, el agredido se explica adamantino desde el piso: "Qué querés, si ustedes son unos manya mierda”.

preside José Pedro Damiani, ex candidato a la Intendencia de Montevideo; el actual presidente, Jorge Batlle, colorado, es socio de Nacional, lo mismo que el actual intendente, Mariano Arana y el senador Danilo Astori, figuras principales del Frente Amplio (de paso: partido político presidido por el socialista Tabaré Vázquez, quien se inició en la política como presidente del club Progreso): los tres se hicieron presentes en las últimas elecciones del Club Nacional de Fútbol para dar su voto a Eduardo Ache, figura del gobierno de Batlle y del partido colorado.

${ }^{6}$ Véase Alabarces y Rodríguez.

${ }^{7}$ Por décadas, el origen de la palabra "manya” era desconocido tanto por la gran mayoría de los que la proferían como por aquellos que la recibían. El grado despectivo estaba implicado, de todas formas, por su remisión al lunfardo de los inmigrantes, es decir, una voz imposible de transcribir dentro de la ortodoxia gramatical de prensa y medios, celosa de la "pureza" del castellano y servil al diccionario de la Real Academia. Para la sociedad integradora del batllismo, conformada por inmigrantes e hijos de inmigrantes, era tabú la reivindicación del origen, que de por sí implicaba un 
Sin embargo, la prensa deportiva (igualmente poco feliz con el idioma, igualmente pacata y defensora del civismo del Estado) los llamaba “tricolores”, remitiendo a su indumentaria, tomada de la bandera federal de José Gervasio Artigas, con los cromos rojo, blanco y azul. Para el adversario — su origen pueblero y ferroviario hipostasiado en los colores de su camiseta, amarillo y negro— la crónica reservaba los términos "carbonero" y el visionario "aurinegro". ${ }^{8}$ Mientras la sosa fabla de los deportócratas trataba de erigirse en muro de contención, reforzador del pacto cívico, la animosidad estallaba en abyección, sin embargo, dentro de la prensa partidaria: en su sistema de denominaciones, el adversario era un innombrable, cuya existencia era un provisoriato de fraseos vacuos como "el tradicional adversario" o "el rival de todas las horas".

Pero, tras la irrupción de la gallinita, todo cambió; los ofendidos, recordando el fuerte olor que sube con la marea del estuario, no dejaron de replicar con un "bosteros", que dio fragancia para siempre a los colores de Boca Juniors. Se puede decir que, por medio de estos apelativos, las hinchadas resolvieron la existencia del otro y, consiguientemente, la propia. En 1966 comenzaba el fin de esta modalidad cívico-deportiva; con los chanchos y atávicas madres de nuestros mejores huevos, que reaparecían en la neblina de los cohetes y papelería que eran el centro mismo del endomingamiento, se difuminaban los límites del campo de juego y la cerca devenía en la orilla, allí donde el tango dice que es sur, paredón y pampa. Papeles, cohetes, bichos, gritos, eran la manifestación corpórea de aquello mismo que alguna vez se confundiera con el espíritu: el aliento (de la hinchada). Si alentar es enajenar el soplo propio en los colores del equipo, insultar al adversario es actualizar las señas de pertenencia y diferenciación, que en muchos casos recordaban de qué barrio se provenía o cuál se evitaba. Así, por ejemplo, en Buenos Aires, los “cuervos” de San Lorenzo recuerdan como "quemeros", por su cercanía a los basurales, a sus rivales de Huracán, mientras en Rosario los “canallas” de Central mapean como "leprosos” a los Newell's, por su proximidad con cierto leprosario.

No faltará quien pretenda trazar un origen de las pasiones deportivas del Plata en la retensión anal o en el derroche, pero aquí lo relevante es consignar la conversión del insulto en reivindicación totémica, así como el desplazamiento por el cual se difuminó el deporte y, a partir del tablón, garganteado por miles primero y millones después, el aguante, como un evangelio, se apoderó de las ciudades.

Tótem, AgUANTE, TELEVISIÓN: EL FIN DEL DEPORTE

A fines de 2000, "El aguante”, programa argentino de Torneos y Competencias, cubrió el clásico final del campeonato uruguayo y entrevistó, dentro de la barra brava de Nacional, a cierto sexagenario que confesó haber defendido, varias décadas atrás y a pesar

grado de diferencia. Las étnicas y de clase eran borradas, en primera instancia, por la túnica blanca de la escuela pública, laica y gratuita, y por la nacionalidad “uruguaya” que, en el siglo xx, sustituyó definitivamente a la "oriental", que predominara en el siglo XIX y que, de por sí, recordaba su parentesco con las provincias argentinas.

${ }^{8}$ Agréguese “mirasol” al anodino lexicón al que la crónica uruguaya recurre para evadir los términos "Peñarol” o "peñarolense". 
de su fanatismo bolso, a Peñarol, e incluso haber averiado con goles el arco del bolsillo. El ex futbolista, reconvertido en hincha, renegaba de su pasado y, con furia de converso, aborrecía su propia vida, negando incluso la meta básica de los deportistas que son o aspiran a ser profesionales: mejorar su estándar de vida y triunfar, defendiendo no importa qué colores. Su pretérito desempeño con lo pies ya no era siquiera locuras de juventud sino estigma que, pasados los años y ante cámaras, lo ponía al borde del llanto. Un yo pecador que (según confesión de parte) había hecho algo "horrendo", algo que él mismo "no se podría perdonar nunca en la vida”. Los costurones de la herida, de la infamia de haber infligido un golcito ocasional al equipo de los amores (en divisiones menores), acaso no pudieran borrarse siquiera con la semanal penitencia de quedar al borde del síncope bolso, desgañitándose en la tribuna; todo ese aliento incondicional hace incandescente la brecha que se abrió entre deportista (y deporte) e hincha, aunque ambos participen de la misma biografía. El deporte, avatar lenificado de la guerra pero también modelo de la vida ciudadana, se vio sustituido por el culto, por el desplazarse (y reconocerse a sí mismo) a través del aliento, del grano estrangulado de la voz, por un "estar ahí”, no importa el resultado en el césped. Así como el juego ya no es tal, y se transforma en una actitud, en una impronta ética, vitanda, del mismo modo se borraron aquellas primeras y frangollantes identificaciones de clase en favor del partidismo menos segmentable (sociológicamente hablando) del aliento, del corazón hecho un vapor que se adhiere a la casaquilla. Igual que, desde hace décadas, los pudientes rugen con Peñarol y los desarrapados afonizan en la hinchada de River, en un mismo movimiento el espacio sacro del campo de juego se hizo vacuidad, hojarasca verde, mera heráldica de la retirada del deporte y, en su lugar, advino una cultura urbana que ya no reconoce competencias.

En rigor, este buen señor arrepentido no debe recordar que eso que le cambió la vida y lo hizo abominar de sí mismo es un movimiento envolvente, posterior a su memorabilia de balompedista, ya que fue en la década de 1970 en Argentina, y durante la siguiente en Uruguay, que las hinchadas pasaron a reconocerse a sí mismas a partir de la agresión, y a corear con afán identitario “soy bostero (gallina, manya, bolso — término despectivo que pretendió mejorar al bolsillo, que ya no venía cosido sino pintado en la camiseta de Nacional)". La afrenta pasaba a asumirse como tótem benefactor de la tribu (la vencida gallina, el bolsillo fetiche, residuo de aquello que venía adherido a la blusa, la bosta que asperjaba el bajo fondo, el excremento como vianda) y a ser adoptada como grito de guerra. Por un lado, había saltado definitivamente el tapón eufemístico de los deportócratas; por otro, se extinguía el deporte, al menos eso que veintidós individuos de pantalón corto disputaban con una pelota; el protagonismo era asumido por la horda que se apiñaba, en el estadio, en los tablones; los jugadores habían desaparecido tras pantallas de televisión. Al respecto, cabe recordar que el penitente supra accedió a las cámaras recién en su investidura de hincha, porque en sus épocas de atleta reinaba una épica que era más bien un murmullo, la de la radiotelefonía, donde los héroes eran un amasijo de nombres ya que, antes de la televisación en directo, quienes asistían a los partidos eran apenas fracción minúscula de los pretendidos conocedores de fútbol; los relatos deportivos, o las fotos de prensa, amplificaban las leyendas, convirtiendo a los futbolistas en héroes de mitologías pordioseras o grandilocuentes. El relato radial convenía una gesta — la del juego— - a los 
millones que no lo atestiguaban desde las gradas y hacía de jugadores como Abbadie, Corbatta, Santamaría o Sanfilippo figuras menos vistas que imaginadas. Aquellos que llegaban al estadio eran los testigos de ese chimento, los que a su turno estarían a cargo de repetir, siempre magnificando, lo que sucedía en un caldeado campo de juego. Ya como testigos, ya como escuchas, el estadio era una especie de templo que daba lugar a una ceremonia abigarrada pero secreta, un cuchicheo que desaguaba en el mito.

Lo trastornó todo la televisión, sin embargo, y se podría tomar el mundial México 1986, conocido por muchos argentinos como “de la mano de Dios”, como mojón que fija el desplazamiento. Entonces, Steven Spielberg sustituyó la ceremonia inaugural por un mediometraje; las reglas mudaron hacia el fair play (limpieza de juego, limpieza de imagen) y ya las cámaras no dejaban lugar a equívocos: fue con la mano que Maradona le ganó a los ingleses. En ese mundial, también, los mexicanos exportaron para el mundo futbolístico una práctica que incorporaron de las ligas de béisbol de Estados Unidos: la ola. El calor del partido se había retirado de esa cancha vacía y derivaba hacia la tribuna, ungida en estrella del espectáculo; los jugadores, patrocinados por multinacionales, pasaron a cortejar las cámaras, mostrando camisetas por debajo de la que defienden, coreografiando sus goles para el receptor, publicitando su comerciable individualidad, escindida de las reglas solidarias del team que los reducían a un número más dentro de once (en vez de a este colorinche carismático y satelizado). Así como están proyectados hacia fuera del estadio (en las salas de millones de hogares y receptores, participando de las sobremesas o las papas chips, pensándose a sí mismos, más allá de la jugada, en otra toma insuperable, en el mejor ángulo que aparecerá, fatalmente, en cámara lenta), por contrapartida, dentro de la cancha verde, no hay nadie. “Estar pintado”, en la jerga del Río de la Plata, implica una participación meramente decorativa; desde que se globalizó el fútbol, a través del satélite, los jugadores se tiñen, decoran o afeitan: están “sacados” hacia la cámara, hacia el telespectador. ${ }^{9}$ No en vano, las barras bravas del Río de la Plata transcurren de espaldas al partido, saltando, corriendo; se hacen sentir, pero no están ahí para mirar, porque nada queda para ver. En el vacío en que quedó la cancha (término que en Argentina incluye las graderías) se instaló la hinchada, que tribaliza el juego inscribiendo la anatomía en los colores que alienta, ya pintándose el cuerpo, ya investida en las mismas camisetas que debería utilizar el espectral equipo que, alguna vez, estuvo entre el verde y dos metas y que ahora es menos parecido a once humanos que a un holograma, a los figurines de un videojuego (de fútbol) o a un tótem traslúcido. ${ }^{10}$

Dado que, fagocitado por el telespectáculo, el fútbol había cancelado el sentido de la victoria o la derrota dentro de un emporio de torneos y partidos que había hecho de la revancha algo perpetuo, el espectáculo encontró una prótesis compensatoria, que además de devolver densidad al evento, y brindarle banda sonora, redefine al hincha, haciéndolo

\footnotetext{
${ }^{9}$ Véase Hamed.

${ }^{10}$ De cuán incorpóreos se han vuelto cancha y deportistas es recordatorio el partido final del Clausura, que a fines de 2001 daba a Racing la oportunidad, disputando un partido de visitante, de volver a ganar un torneo argentino tras siete lustros; dado que las entradas se agotaron en la cancha de Vélez, se instaló una pantalla gigante en el Presidente Perón, estadio de Racing, para que decenas de miles de hinchas pudieran ceremoniar su adhesión en el templo.
} 
parte de la tribu. Cuanto más profesionalizados deportistas y eventos, más comparece el aguante como exaltación de sentimiento desinteresado: a diferencia del viejo espectador (que machacaba el trasero en las graderías, y del telespectador, que se encastilla en su sofá, que disfrutan las jugadas y se descarga festejando un gol o insultando el arbitraje), el hincha tiene una misión, que es la de tener o proveer aguante: salta, corea, alienta, insulta a los adversarios, reta a la barra rival para combatir fuera del estadio, o disputa centímetros de la ciudad para consagrar su sentimiento en paredes y muros. Se atribuye protagonismo, pero su gloria no necesariamente coincide con el resultado deportivo; más aún, en ocasiones le va en contra. Si, para la crónica deportiva, el campeonato que ganó Racing en 2001 marca el regreso a la victoria de un "grande” que llevaba siete lustros suscrito al perdedero, para la hinchada es exhibicionismo cuántico de la pasión: treinta y cinco años de aliento en la derrota. ${ }^{11}$ Se trata de un flashing del sentimiento; a diferencia del público, la barra brava ni siquiera mira el partido: es ciega al match como es ciego el amor (y como el amor, necesita ser gritado, coreado, compartido; en definitiva, proclamado). Ni bien reconoce el descalabro que ha provocado, Edipo se arranca los ojos; nuestro amigo el bolso sexagenario ya no mirará el juego que amó. Su purificación la buscará en el turbión ronco de la barra brava, arrebatándose en el hervidero de orillas lanzadas al agujero negro en que quedó reconvertido el centro. Ciego y autolacerado, Edipo se convierte en figura arquetípica del sufridero; pero Edipo era figura trágica, que desaparecía de la escena. Aquí, por el contrario, rige el desvelamiento de la aflicción, la obscenidad del melodrama, género que suplantó a aquella épica nacional que coagulaba en el deporte.

\section{LA PASIÓN MANDA}

Si bien le brinda mayor capacidad de exposición y, por lo tanto, vuelve más palpable el sentimiento (y es por eso uno de los eventos más acariciados por el aguante), sería una imprecisión considerar la derrota como algo deseado; el aguante, por sobre todo, es un alevoso streap tease de la resistencia y por lo tanto el revés, sea deportivo, sea bélico, no es más que un percance. Aguantar es transcurrir por barrios o provincias tras los colores que han teñido definitivamente el soplo, baleándose con barras rivales, faenándose en escaramuzas o patoteando a los que se internan por el territorio propio, aunque estos no sean más que peatones desprevenidos (esto implica una embestida, de todos modos, contra la integridad de la adhesión y amenazaría la reconversión de calles, barrios o villas miseria en espacio público, tabú para barrabravas cuyos tótems, contrariamente a lo que hubiera pensado Freud, están lejos de la prohibición del incesto). “Batallar”, por ejemplo, para infinidad de montevideanos poco privilegiados, es una forma de vida, consistente en salir en busca del vino o el desayuno, evadiendo el arnés del laburo, cuyo balance es apenas menos instantáneo que las evaluaciones del I Ching: "hoy gané/hoy perdí, mañana se verá”.

¿Pero dónde, entonces, el nexo del aguante como actitud política, como acto de reivindicación ciudadana por el cual gremios y asociaciones civiles asaltan las plazas, es decir, las ágoras y cabildos (rebautizándolas como “del aguante”), con este enconado

\footnotetext{
${ }^{11}$ Ver nota 10.
} 
resistir, que es un culto, alimentado por sustancias, saltos y cantos de posesos, que es asimismo la búsqueda de un éxtasis? Según el aguantar de la barra brava, que no puede quedarse quieta y se avecina a la bacante, a la manía (al punto que no sabe de exclusiones de género y que, parejamente pintadas, o camiseteadas, las mujeres se pelean en las plateas de las damas ${ }^{12}$ ), quien no salta y celebra es un "amargo", por ejemplo el plateísta que observa arrellanado y obediente: ¿por dónde, por tanto, el parentesco con una institución tan poco dionisíaca como las Madres y Abuelas de Plaza de Mayo? Si gallinas, manyas, quemeros, bolsos, leprosos o bosteros clamorean, partido a partido, su enemistad con la polis y su brazo sometedor - la policía—, autoexaltándose como criminales ${ }^{13}$ y minimizando a los rivales bajo el rubro "vigilante", ${ }^{14}$ ¿cómo recuperar esta agitación de posesos en actitud política?

Por irresistible o tentador que resulte acusar a la globalización de esfumar distancias entre patria y bandolerismo, ${ }^{15}$ en rigor es incluso más difícil excluir, como hipótesis vinculante, al imperio del melodrama. Al respecto, baste recordar que, entremés primero, metódico festín del cáncer después, Evita, es decir, la pasión de Evita, le dio un espesor emocional al peronismo y que, por más amargas que se las vea — precisamente cuanto más desafectas a la satiriasis o el raterismo — las Madres y Abuelas, tomadoras atávicas de la

${ }^{12}$ Esto es frecuente en los estadios de Buenos Aires y, en rigor, estas peleas no son unisex ni están confinadas a la platea. También las damas pelean en las tribunas, y arremeten contra los hombres. Consígnese, de paso, cierta anécdota, que muestra cómo esta es una actitud que trasciende las graderías. En 1988, en un pub de Rosario, a Fernando Gamboa, entonces zaguero de Newell’s Old Boys, se le ocurre cortejar a una muchacha y le informa su condición de futbolista. Al detallar los colores que lo han contratado, ella, recíproca, lo abofetea y le explica que jamás saldrá con un leproso.

${ }^{13}$ Baste como ejemplo uno de los cantos de la hinchada de River, que va presentándose y enumerando sus virtudes: “el que no es chorro es criminal/ el más cobarde mató a su madre/y el más valiente, 'pa que vamóa contar./ Cuide señora su gallinero, porque esta noche vamo’a afanar”.

${ }^{14}$ Así, para limitarse a una muestra, este añejo cantito de la barra gallina que dice "no somos como Boca que son vigilantes/a River yo lo sigo porque yo lo quiero/no somos tira tiros como los bosteros/ Porque tenemos huevos vamos a todos lados./ Siempre de la cabeza, todos descontrolados”. O este, que explicita el término "tira tiros”: "Los bosteros son así, son todos putos y vigilantes/ cuando tienen que aguantar, salen corriendo por todas partes./ Es mi ilusión volver a verte, y en cualquier cancha correrte/ sos un botón sos un cagón, sos como el Rojo, sos como el Ciclón./Ay che bostero, yo no te entiendo, vos ves a River y salís corriendo./Ay che bostero, yo no me olvido, que vos a River le tiraste tiros”. De todas maneras, esta sintaxis es enteramente transitiva. Por ejemplo, la barra de Boca canta “Quiero jugar contra River/y matarles el tercero/quiero correrlos de nuevo/de la Boca al gallinero./River vos sos un cagón/porque no tenés aguante/los pibes están en cana/porque vos sos vigilante”.

${ }^{15}$ Alabarces y Rodríguez han señalado como hecho simbólico el regalo, por parte de América TV, de una bandera gigante "con los colores argentinos, el logotipo del canal impreso en su parte inferior, y una leyenda que rezaba Argentina es pasión (siendo el lema del canal América es pasión)” como gesto que pretendía apaciguar localías y tribalismos. "La bandera, símbolo por excelencia de la patria, metonimia de la Nación, señalaba la unidad nacional al tiempo que se transformaba en territorio de los sponsors. Mientras tanto, amparados por la cobertura momentánea, decenas de rateros amenazaban a los espectadores que se hallaban debajo de ella para que les entregaran sus pertenencias. Así — concluyen_-, entre la sponsorización del patriotismo y la delincuencia, circulan nuestros argumentos nacionales”. 
Plaza hoy conocida como “del aguante”, son la heráldica misma de la pasión: su legitimidad proviene del sufrimiento, consagrado en un pañuelo blanco, ${ }^{16}$ y con ella se hacen voz política. Del mismo modo que desapareció el dirimir arbitrado del deporte, en el foro ciudadano, en tiempos de escasez ideológica, el dolor, reconvertido en ideología - o el sentimiento hecho narrativa maestra-, devino argumento excluyente: se tiene razón si duele; la pasión manda. ${ }^{17}$

Dentro de la lógica del aguante — ya cívica, ya pelotera — lo pasional deviene en enunciación privilegiada, en trance y reclamo ético. Así, a cambio de amor y sufridero megafónico, de ese estar siempre ahí y no borrarse, entre otras cosas, el futbolista se ve obligado a proveer dinero para que la hinchada, además de comprar el vino y demás estimulantes, lo apoye durante el partido. Si es protagonista del espectáculo y autoasumido sostén moral del equipo, es impensable para el barrabrava pagar entrada: si la directiva no las provee, ${ }^{18}$ interpelando al prójimo a través de un pansentimentalismo, de su "vivir en el sentimiento" (y no de la solidaridad), limosneará hasta que haya monedas que se la paguen. Totalizados detrás de los colores, estos saltarines extáticos reclaman, como las hierodulas, favores por su trance: sirven al templo y de él viven. Por contrapartida, Madres y Abuelas, totalizadas en su pasión de genitoras desposeídas del fruto, exigirán en nombre de esa prole difunta que, por una suerte de arrebato mediúmnico, habla en ellas. ${ }^{19}$ En una argumentación, ese trance es coartada áurea para descalificar y reducir a escombro moral al adversario, y en adversario puede convertirse quien no participe del júbilo por un acto de violencia. Más aún, su pasión las vuelve inimputables (en tanto, quien exponga disenso se transforma, en el mejor de los casos, en avatar del amargo): si el barrabrava está más allá del trabajo, de las reglas vulgares de la economía y del requisito de abonar entrada, los actos o declaraciones de una Madre, a su turno, están más allá de pedidos de aclaración. ${ }^{20}$ Un rasgo no menor del aguante es ser blasón de la supervivencia (en la más cristiana de sus acepciones: testimonio, mudo o charlatán, de un padecimiento).

${ }^{16}$ Aquí, lo irresistible es recordar que, hasta la década del cuarenta, en Uruguay ni siquiera se gritaban los goles y los partidarios de Nacional, para festejar, agitaban pañuelos blancos.

${ }^{17}$ Por ejemplo, la senadora uruguaya Marina Arismendi, hija del desaparecido secretario general del Partido Comunista del Uruguay, en tiempos de elecciones reconvierte lo que otrora fuera — dentro de su discurso-lucha de clases por un pánico dolor ante los niños pobres, las madres que van a pedir leche a centros de asistencia, etc.

${ }^{18}$ Generalmente, las barras bravas tienen connivencia con las directivas, que les dan las entradas. Ocasionalmente, esta relación se rompe, y quedan expuestas a conseguir por sí mismas pasaporte al santuario.

${ }^{19}$ Se recordará la tenaz oposición de las Madres a que Charly García realizara un simulacro, durante un recital, de los desaparecidos siendo arrojados al Plata. Ese memento, que hubiera sido tolerado, e incluso celebrado, si expuesto en una película, debía ser prohibido en un evento. Porque sufrían, las Madres tenían razón: la ciudadanía argentina, y las demás que padecieron el Plan Cóndor, no podía "vivir" ese momento de la historia argentina. De haberse realizado lo que proponía García, muchos hubieran podido "hacer carne" lo que, por definición de la gramática imperante del melodrama, es patrimonio de los parientes.

${ }^{20}$ Aquí basta recordar a Hebe de Bonafini, reduciendo con el convencional "lacayo del imperio", variante política del bostero o leproso, a Horacio Verbitsky cuando éste criticara el festejo público de la Madre por los atentados terroristas del 11 de setiembre de 2001, en Washington y Nueva York. 


\section{AguANTE ROCK AND ROLL}

Si la atmósfera planetaria recalienta, la de las ciudades platenses hierve en el vibratto barrabrava: se trata no sólo de una suerte de manipulación sintética del grano de la voz, que se ahueca y exalta en el aula, en la vereda, en la confitería o en el micrófono que toca los labios de gremialistas o transeúntes pidiendo se expida sobre la "corrupción de los políticos” en Argentina, o las medidas “antipopulares” de un gobierno uruguayo que procura supervivencia gravando a las "mascotas vertebradas que no sean perros". ${ }^{21}$ Pero repiquetea también en plena lengua del cuerpo, bajo los láser mareantes de las discotecas, en esas camisetas que encapsulan también a los “niños bien”, por si la noche y el mareo derivan en festival de trompadas; o en la altanería con la que un adolescente de balneario, atigrado en la camiseta de Peñarol, baja en mitad de la canícula a caminar por la orilla, tras alguna derrota clásica, el tórax una púa en espera de cualquier broma eventual; o incluso en la niña de menos de nueve, entrajada con la diez de Nacional, que mira hosca hacia otra parte ni bien llega la monserga de masticar el sushi con la boca cerrada.

Aguante o garra retráctil, resistencia desafiante que desconoce edades y desagua en barullo, ya de cacerolazos, ya de altoparlantes que estallan a las cuatro de la mañana, asordinando motores de camión o de autobuses, en cumbias del orto, ${ }^{22}$ cuplés de murga, riffs de los Rolling Stones o craso tamborileo. No importa si viene de la radio de un Mercedes Benz, de cd players o altoparlantes: si el aguante interpela por la pasión, su etos, su osamenta moral, se ha hecho pasta de rock and roll, a condición de que éste se rectifique y reconvierta en cumbia villera, batucada, milonga de Zitarrosa o samba andina: cualquier ritmo es canto bélico que hecho un polvillo se hace granulación del alma y tónico del empaque. A nadie debería alarmar su omnipresencia, ya que desde un inicio el aguante fue, por sobre todo, un esfuerzo pulmonar y melódico: como los templos protestantes, el tablón

${ }^{21}$ En diciembre de 2001, la cámara de diputados aprobó un proyecto de ley que gravara a estas mascotas (los perros habían sido taxados algún tiempo atrás). Es de columbrar que el aguante ciudadano mostrará su ingenio evasor adoptando espongiarios como alegría de la casa; no será de extrañar que, entonces, la voluntad del Estado, famosamente presupuestívora, enmiende el vacío legal y comprenda también el polvillo estelar y todo lo que se vea bajo un microscopio.

${ }^{22}$ Canción de gran popularidad en Uruguay, que llegó primero a Argentina en transcripción periodística, debido a la cobertura de Página 12 del partido entre Uruguay y Brasil en el Estadio Centenario. Como preliminar hubo un espectáculo musical; la reseña de Página 12 dice así: "La Auténtica se llama la banda de cumbia más popular de Uruguay, y por eso la invitaron a tocar en vivo en el Centenario minutos antes del partido. La cancha era una fiesta anticipada, la gente bailaba y cantaba como si el triunfo ya se hubiese consumado. Entonces fue el turno del hit de La Auténtica, la elíptica ‘Cumbia del orto' (sic), cuyo estribillo dice, precisamente: 'Me gusta la cumbia/ la cumbia del orto'. Que todo el estadio cantase el estribillo a los gritos ya de por sí era un lindo espectáculo. Pero lo mejor llegó cuando el cantante arengó a la multitud cambiando la letra: en lugar del estribillo, propuso ‘A los brasileños/ le rompemo’ el orto'. Y obviamente la multitud se prendió. Lo mejor fue que mientras todo el estadio cantaba el pegadizo estribillo escatológico, los jugadores brasileños estaban ahí, precalentando, a unos veinte metros de la banda. Como para hacerles sentir la famosa garra charrúa”. En el partido Uruguay-Australia, que definió la clasificación para el Mundial 2002 se reiteró el preliminar y esta vez el vocalista de la Auténtica, antes de comenzar la canción, como atacado por un pudor, dijo: "a los australianos les vamos a romper el...”. Las tribunas (compuestas en esta oportunidad mayoritariamente por público, y no por barrabravas) contestaron a medias. 
se había convertido en escuela de canto $^{23} \mathrm{y}$, como las primeras iglesias, en evangelio acarreado por legión de mensajeros.

Llámese aguante hímnico aquel corear en contrapunto que provoca estupefacción entre los roqueros que llegan al Plata para descubrir un público — décadas de calistenia coreuta - singularmente participativo y afinado. Esta variante ha sido estrictamente continentada por estadios y, como yuxtaposición canónica de la ética del aguante y la del rock, se pueden consignar los primeros toques de Los Redonditos de Ricota, en las vísperas de los 1980: los conciertos eran proclamados por la banda de La Plata, y así fueron entendidas por multitud de adolescentes de escasos recursos, como "llamadas a misa". La compostura de santuario de los estadios quedaba intocada: resultaba indiferente lo que hubiera en su centro, si escenario o cancha, pero crucial era el mantenimiento del armatoste neumático (dicho de otro modo, del fuelle vinculante). Se puede decir que, en buena medida, no era más que revival de una ética tan revenida como roquera: la de participar en misas de ricota igual que, en las primicias del rock, adolescentes que comenzaban a esquivar al barbero acudían a los antros donde sonaban unos núbiles Rolling Stones. En buena medida, se repetía en los Redondos el vetusto aspaviento desafiante del rock and roll, su explosión sonora, el convite al descontrol y, más aún, su ética de vanguardia excluyente que obliga a renegar de todo lo demás, la convocatoria a un estilo (estético, vitando, o de aguante). Por dejá vu que parezca este misal, lo cierto es que los Redondos, a diferencia del mainstream del rock argentino, que era de clase media, convocaba a los márgenes y la adhesión resultó tan membruda que, hasta el día de hoy, existe un aguante ricotero, indistinguible en lo formal del deportivo ${ }^{24} \mathrm{y}$ las barras siguen peregrinando por toda Argentina o buscan un estadio en Uruguay para no perderse el próximo servicio.

De todos modos, como no se ignora, jamás tablón o cemento contentó a las barras, y sus cabriolas y grito melódico siguen apuntando a la ciudad, o a un punto en lontananza donde aguarda un nuevo partido o combate; ${ }^{25}$ llámese melódico totémico a la desaparición del estilo roquero (en Argentina, entre otras reglas, la feminización y afectación de la voz de Luis Alberto Spinetta, el primer Charly, David Lebón, Miguel Abuelo o Gustavo Ceratti) que puede traducirse, también, como la desaparición del contrapunto en favor de la turbonada del coro. Y acaso el primer indicio de que estos cantos de guerra habrían de devenir contaminación sonora haya que encontrarlo en cierta conmovedora celebración de la cobardía de la barra, intitulada "Vení Raquel”, ${ }^{26}$ a cargo de Los Auténticos Decadentes, banda que multiplicó éxitos pop en Latinoamérica. Todavía hoy, la banda es liderada por

\footnotetext{
${ }^{23}$ Aunque lejos del gregoriano, este canto exige una modulación particular. Así como Gardel superponía una $r$ al sonido $n$, el héroe múltiple y saltarín suele ubicar una $u$ donde se esperaría encontrar una $o$; la inflexión, además, comporta cierto ahuecamiento de la voz.

${ }^{24}$ De todas formas, el reclamo de exclusividad en la adhesión parecería hacer divergir a ricoteros e hinchas de fútbol: hasta el presente, los cantos de las hinchadas, todavía no han adoptado ninguna canción de los Redondos.

${ }^{25}$ Ese saltar y cantar maníaco, por otra parte, no distingue entre lo real y lo virtual: a menudo, en foros de discusión de Internet, las barras fijan el lugar donde se encontrarán para pelear: resistir en la pelea, implica lo mismo que estar siempre ahí, que no borrarse. Quiere decir "tener aguante”.

${ }^{26}$ Los lyrics de "Vení Raquel” son una descripción definida que a muchos podría hacer recordar el relato "Las fiestas del monstruo”, de Bustos Domecq; sin embargo, su riqueza está en la destitución
} 
Cucho, cuya etiqueta en los conciertos era por entonces la camiseta de Boca y cuya audacia canora consiste en descartar cualquier impostación de voz distinta del coreo barrabrava. Por supuesto, melódico totémico y aguante hímnico distan del antagonismo, siquiera de la discrepancia y, en buena medida, resultan complementarios: el segundo celebra la pasión; el primero, a la barra.

Ambos, por otra parte, han confluido, a través de un itinerario precisable, hacia ese mix o rocío aturdidor que impregna las ciudades. Si en Uruguay, antes del paréntesis de la dictadura, el rock se había sincretizado primero con el candombe a fines de 1960, por obra de Eduardo Mateo, y una década después por la anexión de la murga al sonido eléctrico que hizo Jaime Roos, en Argentina sólo el tango, música ciudadana, era arreglo ocasional en canciones de Spinetta, Charly o Fito Páez. Cuando Divididos, el grupo liderado por Mollo, pasó en la década final del siglo a incorporar folclores de provincia como chamarritas, zambas, carnavalitos, etc., encontró replicante en Soledad, que acompañada de músicos “desenchufados” canta desde malambo a chamamé con actitud y entonación roquera, haciendo hélice de su poncho y saltando por el escenario. La tropical bailanta, otrora coto exclusivo del pobrerío, no fue ajena al proceso, con escena carismática y garganteos reminiscentes del rock en solistas como los cordobeses La Mona Jiménez o Rodrigo (cuyo gran hit fue la celebración hímnica, estilo tablón, de Maradona). ${ }^{27}$ Por otra parte, mientras eran las bandas tropicales de hombres barbie — se pueden consignar reflejos en las camisas entalladas que descubren medio tórax, reflejos en la melena batida - los que adoptaban el ya arcaico glam del rock de los setenta, los roqueros pasaron a adoptar un look chabón y deportivo — short y zapatillas, o equipos de gimnasia- ${ }^{28} \mathrm{y}$ a tensar la cuerda abierta por Los Auténticos. Desde el ritmo ska y bandas como La Mosca o Bersuit Vergarabat, en Argentina, o La Vela Puerca, en Uruguay, la entonación del tablón se ha vuelto norma en los solistas, en tanto los que remiten todavía a los antiguos estilos roqueros no evitan celebrar el aguante. ${ }^{29}$ Todo este eclecticismo, de todos modos,

de toda ironía: “Ay cuando conocí a Raquel/se zarandeaba provocativa/para mirarla de atrás/se daba vuelta toda la esquina/yo la quería encarar/ay, pero solo no me animaba/fui hasta el café, busqué a mis amigos/y la encaramos en barra./ Vení Raquel, vení con los muchachos/vení Raquel, te vas a divertir/vení Raquel, vení no tengas miedo/vení Raquel que vas a ser feliz/vení Raquel, vení con los muchachos/que te vas, ay, te vas a divertir./ Yo la conocí a Raquel/era una gorda que ni te digo.../ Cuando la conocí a Raquel/se me ponía la piel de gallina/para mirarla de atrás/se daba vuelta toda la esquina". De hecho, se la podría considerar documento del pasaje de las mujeres a la "actitud barrabrava”.

${ }^{27}$ El otro fue "Soy cordobés”, cuyo estribillo dice “Soy cordobés, me gusta el vino y la joda y lo tomo sin soda porque así pega más, pega más, pega más”. Luego explica: “Como creyente yo le doy gracias a Dios por esta bendición que en la sangre llevamos, es todo el año ‘tunga tunga' del mejor, es nuestro rocanrol y a la Mona idolatramos".

${ }^{28}$ Spinetta, patrocinado por Adidas, comenzó a presentarse en conciertos con equipo deportivo desde comienzos de los noventa. Un roquero pasaba a ser patrocinado lo mismo que un futbolista; sin embargo, el look chabón, al menos por ahora, no sabe de patrocinios. Se dedican a tocar vestidos como en el barrio, o de entrecasa.

${ }^{29} \mathrm{Si}$ bien siguen siendo estrictamente roqueros, Jorge Nasser o Gabriel Peluffo, en Uruguay, mantienen la tradicional entonación y ritmo roqueros (el primero del "pesado" de los sesenta y setenta, el segundo del punk), no han podido abstenerse de cantar al fútbol y, por sobre todo, la actitud 
vivía encriptado en los estadios y la omnivoracidad esquiva a estilos de la barra, cuyos cantos degluten los últimos hits (provengan del rock, del cuarteto, la cumbia o baladas de Natalia Oreiro) y dan cuenta, en rigor, de un sincretismo: en un ritual carismático que el canto enhebra, deidades de mundos heteróclitos son bienvenidas y la bandera del cuadro de los amores es cotorro hospitalario para el rostro del Che y la lengua de los Rolling Stones. El matrimonio del argentino Mollo con la uruguaya y pop Natalia Oreiro (despreciada por las revistas roqueras especializadas), impensable en algún otro momento por incompatibilidad disciplinaria, se consumó, sin embargo, a inicios de 2002: el templo del aguante prescribe ese maridaje.

Yo NO TENGO NOVIO, PERO TENGO AGUANTE

Al paso del autobús, a lo largo de la ruta que lo traía desde Punta del Este, kilómetro tras kilómetro, abuelas mechudas, padres calvos o grises, adolescentes y niños se prosternaban. Era un domingo, 25 de noviembre de 2001; la selección uruguaya iba en busca del Estadio Centenario y la clasificación a Corea/Japón 2002, en un partido final contra Australia. Este aguante postrado - y en la postración exigente- era apenas anagnórisis de la marginación global en que habían quedado no sólo los ciudadanos sino también su canciller más notorio: el balompié. En el partido no habría nada para ganar (era una eliminatoria), ni siquiera esperanzas; se trataba, simplemente, de no abismarse más en el escalafón de países. ${ }^{30}$ Tras esa sobreexposición del sentimiento, que comportaba servir la cabeza flagelante ante el abrupto rodado que secuestraba el almita fracturada, ¿cuál habría sido el aguante celeste, en caso de haber sido, una nueva vez, bienvenidos por la derrota? Es decir, qué manifestación encontraría la ortopedia adherente que esperaría - como los indios que regrese el ciclo favorable en que se reapropiarán de los Andesun nuevo mundial, otra oportunidad de subirse al mundo bajo rubro deporte. Si es ardua la conjetura, un poco menos lo es barruntar que el omnívoro aguante contiene su correlato geopolítico: en un planeta gobernado por la gramática de ganadores y perdedores que impuso un imperio y que se ha convertido en evangelio de transnacionales, el aguante, esfinge que transcurre por fuera del imperativo del trabajo, del decoro cívico-nacional, que deshace la distinción entre los que ganan y los vencidos, es una reivindicación de los márgenes. Si Los Auténticos ya ni siquiera se molestaban en proponer solista, con el coro suplicando/exigiendo un ano penetrable en “Entregá el marrón”, los niños y adolescentes de Montevideo se han convertido en peaje sin fin, exigiendo monedas: la ética de la barra se transforma en moral ciudadana; simplemente "estar (por) ahí” legitima en ellos la mendicidad, porque no se trata de carenciados. ${ }^{31}$ Ni más ni menos que aguantar como

de la hinchada. Nasser componiendo el tema musical de Pasión, programa deportivo, Peluffo con "Cada vez te quiero más".

${ }^{30}$ Richard Giulianotti sostiene que, a pesar de que los indicadores objetivos (económico-sociales) no son señal de un futuro "negro", los ciudadanos uruguayos son los más pesimistas de América Latina y que esto está estrechamente vinculado al declive en el desempeño de su selección de fútbol y de sus dos "grandes".

${ }^{31}$ Esto no deja de reconocer el hecho de que la mitad de los niños uruguayos de 0 a 5 años y el $40 \%$ de los de 6 a 13 años vivan por debajo del umbral de pobreza; pero lo significativo dentro de la 
sustituto de vivir; así por ejemplo, tras cantar adhesión por Peñarol y la caja de vino, Samantha Navarro, roquera de esta ciudad, impone en el estribillo que: “yo no tengo novio, pero tengo aguante”; si el imperativo es tener pareja, el aguante llega para cubrir, como una cobija, lo que no se tiene y acaso ni siquiera se desea. Ciertamente, aguantar implica gambeta al sometimiento, pero acaso sea asunción, también, de que nada queda por ganar (ni novio, ni torneo, ni un ascenso laboral, acaso tampoco fama); en este sentido, deviene negación del mundo, o de las reglas que ha impuesto el mundo. Pero dista este dribbling de la evasión predicada por el diván o el wrestling de clases; es compensatoria prótesis, que adhiere al mundo (sin desconocerle existencia) para no orbitar en lo vacuo. ${ }^{32}$ Una de esas piernas ortopédicas, arrojada desde helicópteros sin rostro, para el amputado que pisó una mina.

\section{Bibliografía}

Alabarces, Pablo y María Graciela Rodríguez. "Football and Fatherland: The Crisis of National Representation in Argentinian Football”. Culture, Sport, Society 3/2 (London, 1999).

Alabarces, Pablo y María Graciela Rodríguez. "Fútbol y patria: la crisis de la representación de lo nacional en el fútbol argentino”. http://www.efdeportes.com/efd10/pamr10.htm.

El aguante. Charly García. Buenos Aires: Columbia, 1998.

“Entega el marrón”. El milagro argentino. Los Auténticos Decadentes y Domingo Guarma (Prod.). Buenos Aires: Kolm, Fasanelli y Zambón, 1989.

“Vení Raquel”. El milagro argentino. Los Auténticos Decadentes y Domingo Guarma (Prod.). Buenos Aires: Kolm, Fasanelli y Zambón, 1989.

Guilianotti, Richard. "Built by the Two Varelas: the Rise and Fall of Football Culture and National Identity in Uruguay”. Culture, Sport, Society 3/2 (London, 1999).

Hamed, Amir. “Metamorfosis del balompié”. Brecha 658/XII (Montevideo, 16 de mayo de 1997).

Tengo recuperación. Samantha Navarro, Rubén Roda (Prod.). Montevideo: Universal Polygram, 2000.

Verdú, Vicente. El fútbol. Mitos, ritos y símbolos. Madrid: Alianza, 1981.

argumentación del aguante es que esta mendicidad es desarrollada, sistemáticamente, por niños y adolescentes pudientes.

32 "Lo que ves es lo que hay" cierra El aguante de Charly García. 